\title{
August Ludwig Schlözer als Sprachforscher
}

\author{
(Erweiterte Fassung des Vortrags in der Gedenkveranstaltung)
}

Helmut Keipert

Ist August Ludwig (von) Schlözer bei all seiner Vielseitigkeit tatsächlich auch als Sprachforscher oder gar als Sprachwissenschaftler zu bezeichnen? Wer die 2003 von Martin Peters veröffentlichte umfangreiche Biographie des Gelehrten durchsieht, wird in der Schlußbetrachtung zu dieser auch das wissenschaftlich-schriftstellerische Werk eingehend analysierenden Dissertation zwar „Schlözer als Historiker“, Schlözer als Europäer („Schlözers Perzeption von Europa“), „Schlözer als Staatsrechtler“ und „Schlözer als Publizist" resümiert sehen, nicht aber eine entsprechende Summe seiner zweifellos anregenden Beiträge auf dem Gebiet der Sprachenkunde finden $^{1}$. Freilich waren für Schlözer das Erlernen und die Analyse von Sprachen niemals Selbstzweck, sondern - im Gegensatz zur Sprachwissenschaft unserer Tage - immer nur Mittel zum Erreichen anderer Ziele: zum besseren Verständnis von Quellen und Fachliteratur, für Gespräche in fremden Sprachen oder aber dann, wenn die Sprachen von Völkern Rückschlüsse auf deren vorhistorische Schicksale zu erlauben schienen. Gerade wegen seiner intensiven Beschäftigung auch mit Sprachproblemen kann sich Schlözer heute einer besonderen Wertschätzung als wichtiger Vorläufer z.B. in der Slavischen Philologie erfreuen ${ }^{2}$, und ähnlich wird soeben in der Geschichte der Ethnologie wieder betont, daß nach Leibniz er es gewesen ist, der Völker primär durch die Besonderheiten ihrer Sprachen voneinander abgrenzen wollte ${ }^{3}$. Wie dieses ausgeprägte Interesse an Sprachproblemen bei dem bekanntlich als Theologe, Klassischer Philologe und Orientalist ausgebildeten Schlözer entstanden ist, scheint allerdings noch nicht hinreichend geklärt zu sein, und deshalb lohnt es vielleicht, einmal ausdrücklich gerade auf diesen Aspekt seines Euvres einzugehen.

1 Peters 2003. S. 433-446.

2 Mühlpfordt/Zeil 1993; Zeil 1994. S. 72-81 [bei Peters 2003 nicht berücksichtigt]; vgl. zu Schlözers Leistungen für die slavische Sprachwissenschaft Lauch 1968; Lauer 1985; Ohnheiser 1985; Udolph 2000; Dörfler/Weiß 2001; Keipert 2006.

3 Vgl. Vermeulen 2008. S. 205-217. 
Wenn bisher von Schlözers Arbeiten zur Sprachenkunde die Rede gewesen ist, dann ging es vor allem um seine Fragment gebliebene „Rußische Sprachlehre“von 1763-1764, um seine im Manuskript erhaltenen „Gedanken über die Art, die russische Historie zu traktieren" aus dem Jahr 1764, um die „Probe Rußischer Annalen“ von 1768, um verschiedene Rezensionen in den "Göttingischen Anzeigen von Gelehrten Sachen" und um die 1802-1809 erschienene Ausgabe des „Nestor“, immer aber und mit besonderer Hervorhebung um die „Allgemeine Nordische Geschichte“ von 1771, denn dieses Buch ist es, das ihn selbst im Abstand von zwei Jahrhunderten z.B. bei Arno Borst in dem Ruf stehen läßt, der „führende[...] Sprachenkenner und Sprachvergleicher der Zeit" gewesen zu sein ${ }^{4}$. Auf der Grundlage dieser Werke kennen wir allerdings das Bild, das sich Schlözer von der Vielfalt und von der Entstehung der Sprachen gemacht hat, erst ab 1764, d.h. seit seinem Aufenthalt in Rußland, während wir noch immer nur relativ wenig darüber wissen, ob und ggf. in welcher Weise er sich schon vorher, also während seines Studiums in Wittenberg (1751-1754) und danach in Göttingen (1755) mit solchen Fragen beschäftigt hat. Zweifellos hat er z.B. in Göttingen bei Johann Matthias Gesner (1691-1761) und bei Johann David Michaelis (1717-1791) eine gründliche philologische Ausbildung erhalten und als angehender Orientalist nicht zuletzt seine Kenntnis von Sprachen vervollkommnet und erweitert. Deshalb kann es auf den ersten Blick durchaus plausibel wirken, wenn Schlözer in der Rückschau 1802 im Vorwort zur „Nestor“-Ausgabe seinen Lesern lediglich mitteilt, daß er ,aus Gesners classisch-filologischen und Michaelis biblischexegetischen Schulen " gekommen sei, als der Historiker Gerhard Friedrich Müller (1705-1783) ihn 1761 als Hauslehrer und Adlatus von Göttingen nach St. Petersburg gerufen habe ${ }^{5}$. Erstaunlicherweise hat er jedoch in diesem Selbstzeugnis völlig unerwähnt gelassen, daß er von 1755 bis 1759, also mehr als drei Jahre, in Schweden gewesen ist und dort viele Anregungen erhalten hat, die deutlich über das hinausgegangen sein müssen, was damals in Göttingen zu lernen war, und die auch seinen Weg als Wissenschaftler in eine andere Richtung gelenkt haben. Es ist gut belegt, daß Schlözer als Schüler von Michaelis „ursprünglich nicht Historiker, sondern Reisebeschreiber und Völkerkundler des Orients werden "wollte ${ }^{6}$ und daß er, mittellos, wie er zunächst war, immer wieder versucht hat, von Dritten die notwendige finanzielle Unterstützung für eine Orientreise zu erhalten, von der er sich

Borst 1961. S. 1501-1502.

Schlözer 1802. S. 96.

Peters 2003. S. 439. 
eine genauere Kenntnis dieser Länder und eine bessere Beherrschung der dort gesprochenen Sprachen erhoffte. Nicht zuletzt in der Annahme, daß er vielleicht von Rußland aus werde in den Orient weiterreisen können, hat er 1761 das Petersburger Angebot Müllers akzeptiert ${ }^{7}$. Vielleicht hat die zitierte Selbstaussage Schlözers im „Nestor"-Vorwort auch dazu beigetragen, daß es in der deutschen Slavistik üblich geworden ist, Schlözers besondere Aufgeschlossenheit gegenüber dem Slaventum allein mit seinem längeren Aufenthalt in Rußland zu erklären und im übrigen mit Wilhelm Zeil etwas optimistisch zu unterstellen, daß ,an der Universität Göttingen seit ihrer offiziellen Inauguration 1737 “ ein „lebhafte[s] Interesse an den slawischen Völkern, vornehmlich an dem aufstrebenden Rußland" bestanden habe ${ }^{8}$. Diese Behauptung von einem in Göttingen von Anfang an feststellbaren Interesse an den Slaven ist bei Zeil nicht im einzelnen dokumentarisch belegt, aber auch Peters deutet 2003 die auffällige Verschiebung von Schlözers fachlichen Schwerpunkten nur knapp an, wenn er am Ende des Teilkapitels über die schwedischen Jahre zusammenfassend sagt:

In Schweden, wo er sich der Naturhistorie und „nordischen“ Literatur zuwandte, übertrug Schlözer unter Anleitung des Skandinavisten J. Ihre die Wortkritik aus dem Bereich der Philologie auf die Historie. Nun verband er seine philologischen, etymologischen und theologischen Forschungsinteressen miteinander. [... ]. Es muß in diesem Zusammenhang auch darauf hingewiesen werden, daß er sich noch vordringlich als Philologe und weniger als Historiker verstand ${ }^{9}$.

Tatsächlich jedoch ergibt eine genauere Überprüfung der bisher für diesen Zeitraum verfügbaren Quellen zu Schlözers wissenschaftlichem Werdegang, daß insbesondere sein Interesse an slavischen Sprachen und am russischen Mittelalter zweifellos schon während seiner Studien in Stockholm und Uppsala zutage tritt (also nicht etwa erst in den sechziger Jahren in St. Petersburg oder danach in Göttingen eingesetzt haben kann), und sehr anschaulich-konkret läßt sich darüber hinaus nachweisen, daß er bei seinem Aufenthalt dort bereits mit den methodischen Problemen des Sprachvergleichs und den Risiken etymologischer Erschließung von Sprach-

$7 \quad$ Anders, als Mühlpfordt (1983. S. 136) meint, war es also nicht nur, „die,Neugier, dieses Reich kennenzulernen', von dem er ,viel sonderbare Nachrichten" hatte", die ihn nach Rußland trieb.

8 Zeil 1994. S. 74. Es dürfte eher ein der deutschen Slavistik schmeichelndes Vorurteil sein, wenn sogar behauptet wird, Schlözer habe Osteuropa und Rußland bereits seit seiner Studienzeit besondere Aufmerksamkeit geschenkt, vgl. etwa Mühlpfordt/Zeil 1993. S. 341: Seit seinem Studium in Göttingen blieb Sch. unter dem Einfluß von Michaelis und des rußlandkundigen Leipziger Popularaufklärers J. Hübner den östlichen, namentlich den slawischen Völkern, besonders dem russischen Volk und Staat, seiner Geschichte, Sprache, Kultur und Reformgesetzgebung zugewandt.

9 Peters 2003. S. 52-53. 
verwandtschaft bekanntgeworden ist (solche Probleme also - entgegen der landläufigen Meinung - nicht erst 1764 in seiner „Rußischen Sprachlehre"zu diskutieren beginnt). Das sprachwissenschaftlich-slavistische Euvre Schlözers hat allem Anschein nach kräftige Wurzeln in der zeitgenössischen schwedischen Wissenschaft. In der gebotenen Kürze soll hier an drei Beispielen gezeigt werden, wie Schlözer, noch in den fünfziger Jahren, philologisch-sprachwissenschaftliche Positionen seines Gastgebers Ihre in Uppsala übernommen und in seinen eigenen Arbeiten später beibehalten und weiterentwickelt hat.

Johan Ihre (1707-1780), der vielen Germanisten als Begründer der Schwedischen Philologie gilt, ist im 18. und im frühen 19. Jh. ein weit über die Grenzen seines Landes hinaus bekannter Gelehrter gewesen. Selbst aus heutiger Sicht ist er noch ein so bedeutender Sprachwissenschaftler, daß er $1996 \mathrm{im}$ „Lexicon grammaticorum. Who's Who in the History of World Linguistics" einen eigenen Artikel erhalten hat, in dem seine wichtigsten germanistisch-skandinavistischen Publikationen genannt und knapp charakterisiert sind: seine Untersuchungen zum „Codex argenteus“ in „Ulphilas illustratus“ (1752-1755), zur Erfassung des regionalen Wortschatzes das "Swenskt dialect lexicon“ (1766), sein monumentales sprachvergleichend angelegtes Schwedisch-Wörterbuch unter dem Titel „Glossarium Suiogothicum“ (1769), seine epochemachende Analyse zur „Edda“ (1772) oder seine Beiträge zur Runenkunde. Erwähnt wird in diesem Artikel auch, daß er wegen seiner komparatistischen, auf einer breiten Kenntnis von Sprachen beruhenden Betrachtung des schwedischen Wortschatzes als ein Vorläufer der Indogermanistik angesehen werden kann ${ }^{10}$. Aus gegebenem Anlaß wäre noch zu ergänzen, daß in den mehr als 450 Dissertationen, über die unter Ihres Vorsitz in Uppsala disputiert worden ist, auch nicht wenige wissenschaftliche Erkenntnisse des Praeses begründet und veröffentlicht worden sind, da es damals nicht unüblich war, daß diese Dissertationen in Teilen oder auch ganz von den präsidierenden Professoren verfaßt wurden und das Disputieren vor allem dazu diente, das argumentative Geschick und die Eloquenz des Respondenten bei der Verteidigung der vorgelegten Schrift unter Beweis zu stellen ${ }^{11}$. In Hinblick auf Schlözers spätere wissenschaftliche Hauptgegenstände lohnt zudem der Hinweis, daß der 1735 als Latinist berufene Ihre ab 1738 in Uppsala die herausgehobene, im 17. Jh. von Universitätskanzler Johan Skytte für die Ausbildung künftiger

10 Holm 1996. Vgl. allgemein zu Ihre nach Holm 1971-1973 jetzt Östlund 2000. S. 20-26; zu seiner Bedeutung als Sprachwissenschaftler auch Raumer 1870. S. 200-204, Grape 1949 Bd. 1. S. 57-132 („Johan Ihre som språksforskare“) und Agrell 1955. S. 78-80, 143-161.

11 Vgl. Östlund 2000. S. 14-19 („The Academic Disputatio and Dissertation“). 
Staatsbediensteter und Diplomaten gestiftete Stelle des Professor Scytteanus innehatte und in dieser Eigenschaft eines professor eloquentiae et politices öffentlich über Geschichte und Politik der europäischen Staaten vortrug, während er privatim auch über Probleme des Schwedischen las, weil er der Ansicht war, daß künftige Verwaltungsbeamte diese Sprache gut beherrschen sollten ${ }^{12}$. Bemerkenswert ist schließlich, daß Ihre auch die politische Auseinandersetzung in der Öffentlichkeit nicht gescheut und 1740 mit einer Dissertation zur Frage „An crescens vicini principis potentia justam belli causam praebeat?" in den unter Schweden virulenten Streit um einen Präventivkrieg gegen das Russische Reich eingegriffen hat, was zur Folge hatte, daß er nach einem dreijährigen Prozeß vor Gericht zu einer hohen Geldbuße verurteilt wurde ${ }^{13}$.

Ihres Einfluß auf die Ausbildung von Schlözers wissenschaftlichem Weltbild läßt sich vorläufig nicht in ganzem Umfang darstellen, weil man dafür nicht nur die soeben genannten Publikationen zu durchmustern hätte, sondern auch genauer wissen müßte, was im einzelnen in den über 450 heute bekannten Ihre-Dissertationen steht und welche davon Schlözer in Schweden oder später in Göttingen zur Kenntnis genommen hat. Auf dem Gebiet der Sprachwissenschaft gibt es meines Wissens wenigstens drei Dokumente noch aus den fünfziger Jahren des 18. Jh., die veranschaulichen können, daß Schlözers linguistisches Denken damals von Ihres Arbeiten beeinflußt worden ist, und danach erkennt man die Wirkung dieser schwedischen Tradition wahrscheinlich am ausgeprägtesten in der „Rußischen Sprachlehre"von 1764, aber sie ist auch in späteren Werken nicht zu übersehen.

Die meines Wissens früheste Nachricht über Schlözers Kontakte zu Ihre liest man in seinen 1794 veröffentlichten Briefen an Michaelis, aus denen wir u. a. erfahren, wie sehr ihn seine Orientpläne und die damit verbundenen Geldprobleme auch in Schweden umgetrieben haben. So schreibt er am 11. August 1757 aus Stockholm, daß er Schweden schon wieder verlassen wolle, um in Danzig eine kaufmännische Lehre anzutreten und dort auch das Polnische zu erlernen („ut Polonice discam“). Gleichzeitig aber berichtet er, daß er vier Monate in Uppsala bei „dem berühmten und mir sehr gewogenen Ihre“ („Cel. Ihrii, mihi faventissimi“) gewesen sei. Warum er gerade diesen prominenten Gelehrten aufgesucht hat, läßt sich einstweilen nur vermuten ${ }^{14}$. Jedenfalls will Schlözer, gestützt auf Ihres Bücher und auf dessen methodisch-fachlichen Rat, damals schon mit sprachvergleichen-

12 Östlund 2000. S. 19-20 („The Professor Skytteanus“), 21.

13 Östlund 2000. S. 22.

14 Nach einem Streit mit seinem Stockholmer Gastgeber Murray ist Schlözer nach Uppsala gegangen, um dort Deutsch zu unterrichten: 
den Studien zur nordischen Etymologie unter Einschluß des Polnischen begonnen haben:

Denn seit ich mich ein wenig den Problemen der nordischen Etymologie zugewandt habe /das war der Fall, als mir bei einem viermonatigen Aufenthalt in Uppsala die häufigen Gespräche mit dem mir sehr gewogenen berühmten Ihre und dessen Bücher gute Gelegenheit zum Betreiben dieser Studien gaben/, begann ich, ohne daß mir Ihre widersprochen hat, zu vermuten, daß man bei einer Untersuchung und wechselseitigen Vergleichung der türkischen, persischen, germanischen und polnischen Sprache etwas Gewisseres über die Ursprünge der Völker würde ermitteln können ${ }^{15}$.

Dabei ist das Polnische von Schlözer zunächst wohl nicht aus wissenschaftlichen Gründen gelernt worden, sondern in der Annahme, daß einige Kenntnisse dieser Sprache hilfreich bei der ins Auge gefaßten kaufmännischen Ausbildung in Danzig sein könnten, die ihm Karl Wilhelm Seele, der Lübecker Handelsagent in Stockholm, vermitteln wollte. Jedenfalls stammt der erste Hinweis auf das Slavische kaum von dem ansonsten recht sprachkundigen Gelehrten in Uppsala, denn Ihre hat 1769 in seinem „Glossarium Suiogothicum “ ausdrücklich bedauert, daß er bei seiner sprachvergleichenden Behandlung des schwedischen Wortschatzes die zweifellos naheliegenden Parallelen im Slavischen nicht habe angeben können, weil ihm diese Sprachen nicht bekannt seien ${ }^{16}$. Vielmehr muß man die zitierte Briefstelle

Upsaliam me contuli, ubi cum commodum non esset, qui linguam germanicam doceret,

Senatus Academicus mihi indulsit eam facultatem. (Buhle 1794. S. 185).

Dabei soll er gehofft haben, von Ihre unterstützt zu werden (Peters 2003. S. 43-44). Ob in diesem Zusammenhang auch eine Rolle gespielt hat, daß Ihre ein Schüler von Michaelis' Vater Benedikt in Halle gewesen ist (Mühlpfordt 1983. S. 134), wissen wir nicht; merkwürdig ist zudem, daß in den Ihre-Biographien beim Aufenthalt in Deutschland nur von Jena (!) gesprochen wird, vgl. Holm 1971-1973.S. 763 oder Östlund 2000. S. 21.

Buhle 1794. S. 181-182:

Nam a quo tempore rei etymologiae septemtrionali aliquantulum operam dedi, quod factum a me est, cum Upsaliae mihi quatuor menses commoranti Cel. Ihrii, mihi fauentissimi, et frequentia colloquia et libri magnam ad colenda ea studia opportunitatem praeberent: suspicari coepi, neque repugnante Ihrio, posse aliquid de populorum originibus certius erui, si lingua turcica, persica, germanica atque polonica examinentur atque inter se contendantur.

Vgl. auch Peters 2003. S. 40.

In der Vorrede zählt der Verfasser die von ihm zur Erklärung schwedischen Wortguts herangezogenen Sprachen auf (nämlich in der als ,schema et methodus totius operis“ wohlüberlegten Abfolge von vetus lingua patria - lingua Islandica - l. Alemannica und $l$. AngloSaxonica - $l$. Moesogothica - l. Celtica - l. Graeca und l. Latina - l. Persica) und beschließt die Reihe mit der Bemerkung:

Optassem equidem, ut Sclavonicarum Linguarum aliquali notitia imbutus fuissem: non enim dubito, quin illae multa contineant, quae Scytho-Gothicis Linguis lucem haud exiguam additura essent: praesertim quum gentes Sclavonicae, perinde ac nos, Scytharum genuina propago sint, Getis permixtae vixerint, illasque hodie regiones teneant, unde primi gentium borealium Statores prodiere. Sed quum nihil aeque reformidem, ac incomperta proferre, curam hanc aliorum indagini relinquere debui. (Ihre 1769. S. II). 
wahrscheinlich so verstehen, daß Schlözer trotz seiner damals sicher noch sehr bescheidenen Beherrschung des Polnischen bereits 1757 versuchen wollte, nach Ihres Vorbild vorhistorische Beziehungen zwischen verschiedenen Völkern auf Grund von etymologischen Übereinstimmungen zwischen deren Wortschätzen festzustellen und dabei auch eine slavische Sprache einzubeziehen, und daß der berühmte Ihre ihm mit seiner reichen methodischen Erfahrung als Sprachvergleicher bei diesem Versuch nicht widersprochen hat. Diese doppelte Erwähnung des Polnischen ist - soweit ich sehe - die bisher älteste Nachricht, die uns Schlözers Hinwendung zum Slavischen erkennen läßt und zugleich, unter Anleitung Ihres, seine Beschäftigung mit Fragen eines bereits das Polnische berücksichtigenden Sprachvergleichs sowie mit der etymologischen Rekonstruktion von populorum origines bezeugt, also mit einem Beweisziel, das er einige Jahre später unter mehrfacher Bezugnahme auf Leibniz, aber auch mit wiederholter Erwähnung Ihres ausführlich in den $\$ \$ 38-42$ seiner „Rußischen Sprachleh-

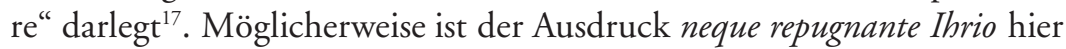
sogar mit etwas Understatement gebraucht, und Schlözer hat Ihre überhaupt erst den Gedanken nahegebracht, daß es erfolgversprechend sei, den schwedischen Wortschatz auch mit dem Slavischen zu vergleichen, denn ursprünglich, in der Vorankündigung des „Glossarium Suiogothicum“von 1755, sind unter den bei den etymologischen Vergleichen heranzuziehenden Sprachen die slavischen nicht genannt gewesen ${ }^{18}$.

In einem weiteren Brief hat Schlözer am 18. Oktober 1757 an Michaelis geschrieben, daß sich seine Abreise nach Danzig wegen der Ereignisse des Siebenjährigen Krieges verzögert habe, und zudem habe ihm Seele, bei dem er sich bereits über Fragen des Handlungswesens unterrichte, geraten, noch in Schweden zu bleiben, um Botanik zu studieren und nordische Sprachen zu lernen ${ }^{19}$. So ist er nach Uppsala zurückgegangen, hat dort bei Carl von Linné (1707-1787) gehört und gewissermaßen aus erster Hand die Ordnungsprinzipien des von diesem gelehrten „Systema naturae“

17 Bulic 1904. S. 28-35. So verweist er den Leser 1764 auf „Ihres Schwedisches Glossarium“ (S. 29 \$39), das erst 1769 erscheinen wird, und natürlich ist es nur durch Ihre möglich geworden, daß Schlözer hier immer wieder Vergleichsbeispiele aus dem Schwedischen, Isländischen oder Gotischen („Ulfil.“) zitieren kann.

18 In der sogleich noch genauer zu besprechenden Projektskizze in einer Disputation vom 24. Mai 1755 hat Ihre in etwas anderer Abfolge als 1769 (vgl. oben Anm. 16) lediglich genannt: l. Graeca - l. Latina - l. Celtica, quatenus in lingua Cambro Britannica superstes est - l. AngloSaxonica - lingua veterum Germanorum sive Theotisca, quae in Franciam et Alemannicam dividi solet - domestici borealium regnorum loculi - Islandici libri (zitiert nach Schlözer 1757. S. 273 275).

19 Buhle 1794. S. 187. 
kennenlernen können, die er bekanntlich später zum Aufbau seines eigenen systema populorum nach den von diesen Völkern gesprochenen Sprachen herangezogen hat ${ }^{20}$. Daneben hat er auch seine Sprachstudien mit Ihre fortgesetzt und, wie er Michaelis am 30. Juli 1758 mitteilt, Lappisch sowie Finnisch zu lernen begonnen, also Sprachen, mit denen auch Ihre sich beschäftigt hat ${ }^{21}$.

Schlözer hat, wie man bei Peters nachlesen kann, von Schweden aus in Rostock zwischen 1756 und 1760 in fünf Stücken eine Rezensionszeitschrift mit dem Titel „Neueste Geschichte der Gelehrsamkeit in Schweden“" herausgegeben ${ }^{22}$. Bei nicht wenigen der in dieser Zeitschrift besprochenen Bücher lassen sich thematisch-inhaltliche Beziehungen zu damals schon erschienenen oder erst später erscheinenden Werken Schlözers feststellen (bezeichnenderweise schließt sie 1760 mit einer Anzeige [Selbstanzeige?] des 1758 erschienenen schwedischen Originals seines „Versuchs einer allgemeinen Geschichte der Handlung"!). Mehrere behandelte Titel kann man mit sprachwissenschaftlichen Problemen verbinden, die Schlözer danach aufgegriffen hat. Der berühmte auf Linné rekurrierenden Satz der „Nordischen Geschichte“ („Die Sprachen würden für den Geschichtsforscher, was die Staubfäden für den Kräuterlehrer seyn.") und dessen Vorläufer in der „Probe“ erinnern in dieser Sicht an die die Zeitschrift einleitende Rezension von Linnés Beschreibung der königlichen Naturaliensammlung in Anwendung seines Klassifikationssystems sowie an die Besprechung zweier Bände des grundlegenden Linnéschen „Systema Naturae per Regna tria Naturae, secundum Classes, Ordines, Genera, Species" im vierten und im fünften Stück von 1759 und $1760^{23}$. Noch näher an der Sprachwissenschaft (und an der Nationalgeschichtsschreibung) ist man im zweiten Stück von 1757 bei der „Nachricht von der bevorstehenden Ausgabe eines Schwedischen Glossarii, durch den Herrn Kanzleyrath Ihre“, denn hier zitiert der Rezensent aus einer Ihre-Disputation von 1755 mit dem Titel „Vetustus catalogus regum

$20 \quad$ Schlözer 1771. S. 211, vgl. dazu Lauer 1985. S. 638-641 und Keipert 2006. S. 24.

21 Buhle 1794. S. 196. Daß Schlözers Vorstellungen von diesen Sprachen gleichfalls durch Ihre und dessen Publikationen geprägt sind, sieht man z.B. daran, daß er 1768 bei der Erwähnung der Lappen in der „Probe Russischer Annalen“ auf eine Ihre-Dissertation von 1742 zurückgreift (Schlözer 1768. S. 103). Vgl. zu Finnen - im engeren und weiteren Sinne - auch die „Nordische Geschichte" (Schlözer 1771. S. 246-247,301-315).

22 Vgl. Peters 2003. S. 41-43.

23 Schlözer 1756-1760. S. 1-33 sowie 513-529 und 683-687. Schon 1763/64 findet man in Schlözers „Rußischer Sprachlehre“ eine Stelle, an der Linné wegen seiner erfolgreichen Systematisierung unübersichtlich wirkenden Materials lobend erwähnt wird: „gleich Linnäo, der durch nicht mehr als 24 Klassen seinen Schülern 12000 Pflanzen deutlich denken lehrt" (Bulič 1904. S. 24). 
Sviogothicarum, pars quinta “24 den lateinischen Text desjenigen Teils der Dissertation, in dem der Praeses (!) in Ich-Form (!) darüber berichtet, welche Überlegungen ihn bestimmt haben, die Kompilation eines schwedischen Wörterbuchs in Angriff zu nehmen, das auch den weitgehend unverständlich gewordenen Wortschatz im nationalen Schrifttum der Vergangenheit sorgfältig und nötigenfalls unter Heranziehung verwandter Sprachen zu erklären such $t^{25}$. Zwölf Jahre vor dem tatsächlichen Erscheinen dieses Lexikons als „Glossarium Suiogothicum“ hat Schlözer Ihres schon seit längerem bearbeitetes Projekt für so wichtig gehalten, daß er dessen eingehende Beschreibung auf sechs Seiten seiner Zeitschrift nachgedruckt hat. Wahrscheinlich bezieht sich gerade auf diesen Dissertationsdruck eine ganz allgemein gehaltene Bemerkung, die Schlözer zu derartigen Veröffentlichungen in seiner Vorrede gemacht hat:

Aus der ungeheuren Menge von Disputationen, welche jährlich auf den Schwedischen Akademien gehalten werden, werde ich die brauchbarsten aufsuchen und sie in einem Auszuge mittheilen. Allein diese kleinen Schriften sind hier schwer zu haben. Es wird also meistentheils von der Gefälligkeit der Schwedischen Gelehrten abhangen, ob sie mir dieselben zuschicken, und ihre Entdeckungen durch mich den Deutschen kundmachen wollen ${ }^{26}$.

Unzweifelhaft jedoch eröffnet dieser Nachdruck von 1757 bei Schlözer eine bis in das „Nestor"-Vorwort von 1802 reichende Reihe von Erwähnungen des "Glossarium Suiogothicum“ und des von Ihre als Vorbild genommenen "Glossarium Germanicum" des Leipziger Lexikographen Johann Georg Wachter (1663-1757), wobei häufig auch allein die Namen Ihre und Wachter wie Dioskuren gemeinsam auftreten, um als Chiffren für eine Vollständigkeit und Zuverlässigkeit vergleichender Wörterbücher des Germanischen zu fungieren, wie sie von der slavischen Lexikographie vorläufig nur zu wünschen, also im einzelnen erst noch zu erarbeiten $\operatorname{sei}^{-27}$. Deutlicher als der in der „Neuesten Geschichte“ lediglich wiederholte lateinische Text aus der Disputation von 1755 belegt die mit der „Rußischen Sprach-

24 Titel zitiert nach Östlund 2000. S. 362.

25 Schlözer 1756-1760. S. 270-276.

26 Schlözer 1756-1760. Unpaginierte Vorrede vor dem ersten Stück.

27 Vgl. Keipert 2006. S. 10, 38-39. Auch in der "Rußischen Sprachlehre“ von 1763/64 sind Ihre und Wachter gegenwärtig, etwa in $\$ 39$, in dem Schlözer die verbreitete „Unkunde der Etymologischen Theorie“ mit ihrem als erwiesen anzusehenden Satz „Griechisch, Latein, und Deutsch sind im Grunde nur Eine Sprache" beklagt und dann fortfährt:

Wer noch nicht davon überzeugt ist, muß entweder Wachtern lesen; oder, wenn ihm dieser kein Genüge thut, sich biß auf Hrn. Ihres Schwedisches Glossarium gedulten." (Bulič 1904. S. 29).

Auch in diesem Fall wird das Lexikon lange vor seiner Veröffentlichung schon warm empfohlen. 
lehre“ einsetzende Zitiertradition in den späteren Werken Schlözers, weshalb diesem Ihres „Glossarium“-Projekt interessant und nachahmenswert erschienen ist. Einmal muß ihn die große Zahl der Sprachen beeindruckt haben, die schon bei Ihres Vorbild Wachter im "Glossarium Germanicum“ 1737 und danach bei Ihre selbst bereits in den Jahren der Vorbereitung des schwedischen "Glossariums" seit den fünfziger Jahren berücksichtigt worden sind, und nicht zuletzt auch die von beiden gebotene objektsprachliche Vielfalt des Germanischen sowohl in Hinblick auf die regional und chronologisch divergierenden lautlichen Formen vieler als verwandt anzusehender Wörter als auch bei deren keineswegs einheitlich verlaufender Polysemierung bzw. semantischer Differenzierung. Die in diesen zwei Lexika dokumentierte Fülle teils übereinstimmender, teils aber auch unterschiedlicher Ausdrucks- und Bedeutungsmöglichkeiten innerhalb des Germanischen könnte Schlözer noch in Schweden die Frage nahegelegt haben, ob es sich in den slavischen Sprachen nicht ebenso verhalte, obwohl deren Wortschätze damals bei weitem noch nicht so vollständig erfaßt waren wie der schwedische oder der deutsche. Beeindruckt muß Schlözer auch davon gewesen sein, daß sowohl Wachter als auch Ihre Wörter verschiedener Sprachen nicht allein auf Grund ihrer lautlichen Ähnlichkeit zueinander in Beziehung gesetzt haben, sondern bestrebt gewesen sind, unter Berücksichtigung einer zumindest ähnlichen Bedeutung der betreffenden Lexeme in den verglichenen Sprachen wiederholt vorkommende, also mehr oder weniger regelhafte Entsprechungen in ihrer Lautgestalt zu ermitteln (d.h. etwas Ähnliches festzustellen, wie das, was die historisch-vergleichende Sprachwissenschaft des 19. Jh. als Wirkung lautgesetzlicher Entwicklungen betrachten sollte). Schon Wachter hat 1737 in seinem „Glossarium“ eine lange Liste solcher als Korrelationen auftretender Lautentsprechungen für den deutschen Wortschatz zusammengestell ${ }^{28}$, und auch darin folgt ihm Ihre 1769 mit einer ebensolchen Liste für das Schwedische, mit der er, nach Meinung Rudolf von Raumers, bereits „einen Theil der germanischen Lautverschiebungsgesetze richtig beobachtet" hat ${ }^{29}$. Schließlich waren Wachter und Ihre mit Leibniz davon überzeugt, daß das Germanische, das Lateinische und das Griechische sich aus einer gemeinsamen Ursprache entwickelt haben müssen; Ihre hat dieser Überzeugung nicht nur durch sein „Glossarium“, sondern auch noch durch besondere Abhandlungen „De harmonia

\footnotetext{
28 Vgl. die neunzehnseitige „Sectio III. De Cognatione et permutatione Literarum“ in den unpaginierten Prolegomena von Wachter 1737.

29 Ihre 1769. S. XLI-XLVIII („ratio mutationis literarum in L. Suiogothica“), vgl. Raumer 1870. S. 201 und zu den „wichtigsten Buchstabenvertauschungen des Schwedischen“" (Raumer) auch ausführlich Agrell 1955. S. 150-161 („Ihre och konsonantväxlingen“).
} 
linguae graecae et suiogothicae“ (1770) und „De harmonia linguae latinae et suiogothicae" (1-2, 1771-1773) Ausdruck verliehen ${ }^{30}$. Schlözer hat sich, wohl schon in Schweden, von diesen glottogenetischen Vorstellungen und von der Beweiskraft der Regularitäten in der lautlichen und semantischen Entwicklung bei lexikalischen Parallelen überzeugen lassen. Sehr anschaulich zeigt sich das in den Grundsätzen für den Sprachvergleich, die er wenig später in seiner „Rußischen Sprachlehre“ von 1763/64 entwickelt. Im Vordergrund steht dabei der Versuch, das Slavische in Gestalt des Russischen wegen dessen Übereinstimmungen im Wortschatz, aber auch im grammatischen Bau an die von Griechisch, Latein und Deutsch gebildete Sprachfamilie anzuschließen, wobei Schlözer mit Nachdruck hervorhebt, daß diese Übereinstimmungen nicht etwa durch wechselseitige Beziehungen zwischen diesen Sprachen, sondern durch Urverwandtschaft zu erklären seien ${ }^{31}$. Nachdrücklich betont Schlözer in der "Sprachlehre“ zudem, daß er seine etymologischen Gleichungen nicht willkürlich nach zufälliger Ähnlichkeit, sondern unter Beachtung bestimmter Regeln aufstelle, wie sie z.B. Wachter in seinem „Glossarium“ vorgeschrieben habe ${ }^{32}$, und später hat er solche allgemeinen Grundsätze für den Sprachvergleich z.B. in der "Nordischen Geschichte“ oder im „Chaldäer-Aufsatz" selbst formuliert ${ }^{33}$. Mit der Beachtung dieser Regeln und mit deren wiederholter Bestätigung durch möglichst viele Parallelbeispiele sucht er sich wie Wachter und Ihre von den älteren Etymologen abzusetzen, die sich mit der zufälligen Übereinstimmung einzelner Laute zufriedengegeben haben: „Allein so etymologisiren Wachter, Gesner, Michaelis, und Ihre nicht!“34 Die bei Wachter und Ihre einbezogene große Zahl verschiedener germanischer Sprachen könnte Schlözer im übrigen dazu angeregt haben, 1764 den Lesern der „Rußischen Sprachlehre“ unter Rückgriff auf die „Untersuchungen vom Meere" des Wiener Philologen und Naturwissenschaftlers Johann Siegmund Popowitsch (1705-1774) seine erste Aufzählung slavischer Sprachen zu präsentieren ${ }^{35}$ und, gleichfalls zum ersten (und nicht zum letzten) Mal, das Fehlen „Slavonisch-Rußischer Glossarien“, eines „vollständige[n]

$30 \quad$ Titel zitiert nach Agrell 1955. S. 150.

31 Bulič 1904. S. 29, vgl. auch die Bemerkung in der „Nordischen Geschichte“, mit der Schlözer die bilateralen Kontakte als vorherrschende Begründung solcher Übereinstimmungen ablehnt: Bei unserer heutigen Sprachenkunde befremden uns diese Aehnlichkeiten nicht mehr; wir wissen einmal, daß alle Sprachen, in ihre Monaden aufgelößt, noch Spuren ihres gemeinschaftlichen Ursprungs haben. (Schlözer 1771. S. 316-317).

32 Bulič 1904 . S. 34.

33 Bulič 1904. S. 34-35; vgl. das Regelwerk in Schlözer 1771. S. 108 und 1781. S. 167-168.

34 Bulič 1904. S. 66.

35 Bulič 1904. S. 64 Anm. 19. 
Rußische[n] Wörterbuch[s]“" zu beklagen und an das Defizit eines neben Wachter und Ihre zu stellenden vergleichenden slavischen Wörterbuchs zu erinnern ${ }^{36}$. Zu einem wiederholt gebrauchten Argument ist für Schlözer im übrigen Ihres auf die Lexik des älteren Schwedischen bezogene Empfehlung geworden, daß man heute unverständlich gewordenes Wortgutz.T. im älteren oder neueren Schrifttum verwandter Sprachen finden und dadurch erklären könne ${ }^{37}$.

Mein drittes Belegstück für die ebenso frühe wie folgenreiche IhreRezeption beim jungen Schlözer betrifft gleichfalls einen Dissertationsdruck zu einer von Ihre präsidierten Disputation, nämlich derjenigen vom 13. Juni 1758 über die Fahrten der alten nordischen Völker nach Griechenland. Wir wissen zwar nicht, ob Schlözer dieser Disputation auch selbst beigewohnt oder lediglich den dabei vorgelegten Druck gelesen hat (geschweige denn, wann und wo das geschehen ist) - in jedem Fall aber handelt es sich bei dem genannten Druck um einen Schlüsseltext in seiner Entwicklung als Wissenschaftler. In dieser Untersuchung, zu der Ihre „vermuthlich den Stof [...] hergegeben“ hat, konnte Schlözer die später für ihn so charakteristische Verbindung von historischer Forschung und sorgfältig-kritischer Analyse von Sprachdenkmälern der Vergangenheit in überzeugender Weise angewandt finden und zugleich, aus schwedischer Sicht, etwas Neues über das unter schwedischen Gelehrten vielbehandelte Warägerproblem lesen, also seine vielleicht erste gründlichere Begegnung mit der Geschichte der Alten Rus' gehabt haben ${ }^{38}$. Der Titel dieses Abhandlung lautet in vereinfachter Form:

Disputatio Academica, sistens Peregrinationes Gentium Septentrionalium in Graeciam, cuius partem priorem [...] sub praesidio $\mathrm{D}$ [omini] Johannis Ihre, [...] pro gradu defendet Magnus Olavus Beronius, Uplandus. Upsaliae [1758 $]^{39}$.

36 Bulič 1904. S. 35, 74

37 Freilich bestätigt Ihre damit eine ähnliche Regel, die Schlözer bereits ,aus Michaelis hebräischer Schule" [bekannt war], deren erster Gedanke war, ,wenn im Hebräischen ein Wort nur einmal oder doch sehr selten vorkommt, und seine Bedeutung daher ungewiß ist, so such es in den verwandten Dialekten auf" "(zitiert nach Udolph 2000. S. 460). Vgl. auch Keipert 2006. S. $11-$ 12 und Schlözers dort zitierte Aussagen über Smotrickij und Gusset.

38 Mühlpfordt (1983. S. 136) sieht als Schlözers erste Berührung mit der russischen Geschichte das Bekanntwerden mit dem Tagebuch des Generals Löwenhaupt, des Besiegten in der Schlacht bei Poltava 1709.

39 Vgl. Ihre 1758. In der Auswahlliste der unter dem Vorsitz Ihres in Uppsala verteidigten mehr als 400 Dissertationen bei Östlund (2000. S. 361-363) ist dieser Titel nicht verzeichnet; bei Scholz (2000. S.305-306) wird er nur beiläufig erwähnt, und im Namenregister fehlt Ihre resp. Beronius völlig. Ich verwende das in der Universitäts- und Stadtbibliothek Köln vorhandene Exemplar. 
Im Text wird der Nachweis geführt, daß der in alten Runeninschriften nicht selten vorkommende Ländername Girkia, Girkialant, Girkium, Grikium u.a. keineswegs wie bis dahin üblich allein mit Griechenland identifiziert werden dürfe, sondern sich darüber hinaus auf alle Gebiete beziehen könne, die an dem östlichen Reiseweg der Skandinavier nach Griechenland liegen, also z.B. auf Estland, Finnland, Rußland oder die Ukraine ${ }^{40}$. Mit einem solchen Thema und Ergebnis fügt sich die Ihre/Beronius-Dissertation in der schwedischen Historiographie des 18. Jh. in die sog. „schwedisch-patriotische Geschichtsschreibung" ein, die durch genaues Studium der überlieferten Quellen die z.T. sehr phantastischen Vergangenheitskonstruktionen der älteren, sog. „gotischen Geschichtsschreibung“ in Schweden zurückweisen und an deren Stelle eine nüchternere, realistischere Darstellung der schwedischen Geschichte setzen wollte ${ }^{41}$. Beim Lesen dieser lateinisch verfaßten Schrift konnte Schlözer im einzelnen nachvollziehen, wie durch sorgfältige Plausibilitätsabwägung wahrscheinlich gemacht werden kann, daß nicht alle der auf den Runensteinen mit Girkia in Verbindung gebrachten Männer tatsächlich auch in Griechenland (im engeren Sinne!) gewesen sein müssen, und er konnte zudem erfahren, wie anders als Girkia man den in den alten schwedischen Quellen begegnenden Ländernamen Gardariki zu verstehen hat.

$40 \quad$ Vgl. die Zusammenfassung dieser Abhandlung, deren zweiten Teil auch schon Schlözer (1771. S. 541) nicht gefunden hat:

Huius Graeciae, quae, praeter totam fere Russiam Europaeam et orientale imperium, suo ambitu complexa videtur regiones ad auster veg sitas, a sinu Fennico usque ad fl. Veisel, licet adcurate definire non possumus limites, haut tamen sine fundemento [sic!'] dixerimus, illam ferme respondere $\tau \tilde{\omega}$ austur antiquiorum, utpote quo nomine adpellaverint regiones in orientem projectas usque ad finem Graeciae. Atque adeo quando lapides et monimenta alia testantur aliquem vel austr vel in Graecia occubuisse, incertum hactenus est, in qua Orientis parte decesserit. Perinde dici potest, intelligi Aestlandiam, Russiam aliamve regionem ac vel Hellada vel imperium orientale. (Ihre 1758. S. 48).

41 Vgl. zu diesen beiden Richtungen in der damaligen schwedischen Geschichtsschreibung am Beispiel des Waräger-Problems Scholz 2000. S. 245-321. Interessant ist, daß auch die 1760 (bzw. 1762) erschienene Besprechung dieser Dissertation in den „Göttingischen Anzeigen von Gelehrten Sachen“ diesen Richtungsstreit erwähnt:

[...] Hr. I. geht gänzlich von der bisherigen Liebe der Schweden zum übergrossen Alterthume ihres Reichs, und ihrer Runen ab. Hierzu gehört nun auch die Einschränkung der bisher geglaubten häuffigen Reisen aus Scandinavien nach Griechenland (worauf man denn den Nordischen Ursprung vieler Griechischen Colonien hat gründen wollen). Hr. I. glaubt hingegen, vor dem eilften Jahrhunderte seyn die Gränzen des wahren Griechenlands, und des griechischgesinnten Rußlandes in [sic! ] Norden nicht bekannt gewesen, und gar oft habe man unter dem Titel von Griechenland bloß die südöstliche Küste des Baltischen Meeres von der Weichsel an, bis zur Neva verstanden. [... . Der Irrthum sey zum Theil daraus entstanden, weil man zur Ungebühr, alle Gothen aus Scandinavien hergeleitet, und den Scandinaviern derselben Thaten und Schicksale zugeschrieben habe. [...]. (Haller 1760. S. 417-418, vgl. zur Attribuierung Schimpf 1982. S. 16 und 82). 
Daß Schlözer den lateinischen Text dieser Dissertation nicht nur gekannt, sondern auch gründlich durchgearbeitet hat, wird durch ein einzelnes undatiertes Blatt belegt, das sich in seinem Göttinger Nachlaß befindet und die Überschrift trägt:

\author{
Abhandlung \\ von den Fahrten der alten Nordischen Völker nach Griechenland \\ ein Auszug aus einer \\ den 13 ten Jun. 1758 zu Upsala unter dem Vorsitz des Herrn \\ Johan(n) IHRE, \\ Kgl. Schwed. KanzleiRaths, Ritters vom NordsternOrden, u(nd) Professors \\ der Beredtsamkeit u(nd) Statskunst, \\ gehaltenen Disputation ${ }^{42}$.
}

Dieser lateinische Disputationstext muß Schlözer so beeindruckt haben, daß er nach der Lektüre davon einen Auszug in deutscher Sprache hergestellt und im Anschluß an den vollständigen, auch den Namen des Respondenten enthaltenden lateinischen Titel der Schrift noch begründet hat, warum sie ein besonderes Interesse verdiene:

Sie kan zum Beweis dienen, wie sehr die jetzige Art, in der alten Nordischen Geschichte zu denken, von derjenigen verschieden sei, welche zu Anfang dieses Jahrhundert in Schweden herrschte. Man wird ohne unser Erin(n)ern die Wichtigkeit ihres In[halts?] sehen. Der MisVerstand eines einzigen Wortes (Girkia) hat einen Schwarm von Irrthümern über die ganze Nordische Geschichte verbreitet. Diese Irrthümer werden hier widerlegt $\mathrm{u}(\mathrm{nd})$ ihre Stelle dagegen mit neuen Wahrheiten besetzt, die nicht nur in die Schwedische, sondern vermuthlich auch in die alte Russische Historie einen Einfluß haben dürften. Da der Herr KanzleiRath $\underline{\text { Ihre, }}$ der vermuthlich den Stof zu dieser Probschrift hergegeben, diese Entdeckungen gröstenteils durch Hülfe seiner ungemein starken SprachenKen(n)tnis machet: so leistet er zugleich der Wortforschung einen wichtigen Dienst, indem er sie mit der Geschichte wieder versöhnet u(nd) ihre Ehre rettet, die durch den gelehrten Aberwitz ungeschickter [sic!] Etymologen von Herodot an biß auf Rudbeck [sic! ] u(nd) Björner so sehr viel gelitten hat.

Anders als Peters behauptet hat, liegt hier also nicht die Zusammenfassung der „Kernaussagen“ einer Disputation vor, die Schlözer selbst am 13. Januar [sic!'] 1758 unter dem Vorsitz von Ihre in Uppsala gehalten habe (wenn Schlözer selbst der Respondent gewesen wäre, hätte er gewiß nicht „vermuthen “ müssen, sondern sicher gewußt, daß das Material seiner

42 Niedersächsische Staats- und Universitätsbibliothek Göttingen: Nachlaß August Ludwig von Schlözer, Cod. Ms. A.L. Schlözer II, 2, Nr. 2: „Abhandlung [sic! ] von den Fahrten der alten Nordischen Völker nach Griechenland: ein Auszug aus einer den 13. Juni [sic!] 1758 zu Upsala unter dem Vorsitz des Herrn Johann Ihre gehaltenen Disputation [sic!] “. Der Bibliothek habe ich für die schnelle Anfertigung einer Kopie dieses Dokuments zu danken, Herrn Kollegen Werner Lehfeldt für seine bereitwillige Vermittlung. 
„Probschrift“ größtenteils von Ihre stammte!) ${ }^{43}$. Auch kann es sich bei der zitierten Passage nicht, wie Peters meint, schon um den in Rede gebrachten „Auszug" handeln, weil sie auf Fragen eingeht, die in der lateinischen Dissertation nicht erörtert werden und weil sie mit ihrem zweiten, bei Peters ausgelassenen Satz ihre präsumptiven Leser ausdrücklich auf den keiner weiteren Erläuterung bedürfenden Text der Dissertation bzw. des - offenbar folgenden - Auszugs verweist. Unerwähnt gelassen hat Peters freilich, daß diesem Abschnitt auf dem Göttinger Blatt noch ein weiterer folgt, in dem es heißt:

Der Auszug ist mit möglichster Kürze u(nd) Ordnung gemacht. Man hat die HauptSätze sorgfältig herausgesucht $\mathrm{u}(\mathrm{nd})$ ihnen, mit Weglassung alles überflüssigen, eine neue Verbindung gegeben. Verschiedene hat man aus dem Text herausgenom(m)en und solche, um den Faden der Erzählung nicht zu unterbrechen, in die Anmerckungen gebracht. Wir werden künftig in dieser Art Auszüge fleissig fortfahren, wen(n) uns der Beifall der Leser darin(n)en unterstützen wird.

Zusammen mit der am rechten Seitenrand neben der lateinischen Titelangabe hinzugefügten Notiz „(mit kleinen Lettern)“ scheint dieser zweite Abschnitt darauf hinzudeuten, daß Schlözer seinen wohl noch in Schweden angefertigten Auszug für die Publikation in einer deutschen Zeitschrift bestimmt und sich mit ihm bei Gefallen für weitere „Auszüge in dieser Art“ empfehlen wollte. Um welche Zeitschrift es dabei gegangen ist (und ob sie diesen Ihre-Auszug auch veröffentlicht hat), entzieht sich meiner Kenntnis; gedruckt ist ein solche deutsche Fassung jedenfalls in Schlözers „Allgemeiner Nordischer Geschichte" (s.u.), und man darf annehmen, daß es sich letzten Endes um den hier erwähnten und von seiner in Göttingen erhaltenen Einleitung abgetrennten „Auszug“ handelt. Schlözers Vorrede ist aber auch als solche, ohne den verdeutschten Dissertationstext, von Interesse, denn sie bezeugt mit ihrem Beginn, daß der Verfasser den scharfen Gegensatz zwischen der älteren - „gotischen“ - und der zeitgenössischen - „schwedischpatriotischen" - Geschichtsschreibung in seinem Gastland durchaus zur Kenntnis genommen hat. Als besonderes Kennzeichen der letzteren sieht er, wie das Girkia-Beispiel belegt, die sorgfältig-kritische und auch das historisch Wahrscheinliche bedenkende Analyse der aus der Vergangenheit Schwedens überlieferten Quellen $\mathrm{an}^{44}$ und hebt Ihres breite Sprachenkennt-

43 Vgl. Peters 2003.S. 44. Die dort gebotene Lesung , ungeschickter “ dürfte der als , ungescheuter“ vorzuziehen sein, und statt „Rubdeck“ ist zweifellos „Rudbeck“ zu lesen (dieser Lesefehler wiederholt sich S. 168). Vgl. zu Olaus Rudbeck d. Ä. Anm. 45.

44 Ist es zu viel vermutet, wenn man mit dem durch solche Lektüre geschärften Methodenbewußtsein Schlözers 1767 in Danzig erschienene Preisschrift über den „Lech“ (,Abhandlung über die Aufgabe aus der polnischen Geschichte ,könnte nicht die Ankunft des Lechs in Polen zwischen 
nis deshalb hervor, weil diese ihn in besonderer Weise zu genauerer Lektüre alter Texte befähige und ihm zudem durch seine methodisch abgesicherten etymologischen Vergleiche überzeugendere Rückschlüsse auf die vorhistorischen Beziehungen zwischen den Völkern erlaube. Mit der Aussage, daß Ihre die „Wortforschung [...] mit der Geschichte wieder versöhnet u(nd) ihre Ehre rettet“, deutet Schlözer zudem an, daß das nach den festen Prinzipien eines Wachter und eines Ihre geregelte Etymologisieren mit seinen „neue[n] Wahrheiten“ die schwedische Geschichtsschreibung von den phantasievollen, allein auf willkürliche Wort- und Namengleichungen gestützten Vergangenheitskonstruktionen eines Rudbeck ${ }^{45}$ oder Björner ${ }^{46}$ befreien könne ${ }^{47}$. Anders als das gelegentlich dargestellt worden ist ${ }^{48}$, richtet sich Schlözers Kritik am „Etymologisiren“ in der Historiographie also

den Jahren 550 und 560 u.s.w. erfolgt seyn ' [... ]“ verbindet, mit der er nach seinen eigenen Worten die ganze Geschichte des Lech als Stammvaters der Polen „zernichtet“ und aus dem „Reiche der Geschichte“ in die „öden Reviere der Fabeln und Träume“ verwiesen haben will? Vgl. Peters 2003. S. 96-101.

45 Gemeint ist hier Olaus Rudbeck d. Ä. (1630-1702), vgl. zu seinen Phantasiegebilden auch Scholz 2000. S. 246:

[Rudbeck] Professor für Medizin, Anatomie und Botanik in Uppsala, versucht in seinem großen Werk [„Atland“ bzw. „Atlantica“, H.K.] über die Geschichte Schwedens in der Urzeit zu beweisen, daß unter Platons Atlantis Schweden zu verstehen sei und daß Schweden das Ursprungsland aller übrigen Länder und Völker sei. [...]. Rudbecks Werk erregte außerordentliches Aufsehen in ganz Europa und bestach durch seine meisterhafte Darstellung und seinen Scharfsinn im Detail. In Schweden wurden Skeptiker fast als Landesverräter betrachtet.

Rudbecks Name wird in der Ihre-Dissertation zwar genannt, aber im Zusammenhang mit etymologischen Problemen. Nach der entschiedenen Zurückweisung der These, daß die Verfasser der Runentexte den Ländernamen Girkia in Unkenntnis des tatsächlichen Wegeverlaufs auf ihre Steine gesetzt haben könnten, liest man dort:

Alii ita haec Autorum loca explicant, ut dicant, eos, qui non ignorarunt majorum nostrorum cursus inter Septentrionem et orientem, quod via per varia flumina navigiis portatilibus illis fuerit ignota, omissa mentione itineris per loca, quae Baltici maris fines et Graeciam interjacent, simul transmissum esset saepius nominatum mare, statim in Graeciam ventum esse, scripsisse.

und findet dazu mehrere Stellenangaben aus Rudbecks „Atlantica“ (Ihre 1758. S. 37).

46 Gemeint ist hier Erik Julius Björner (1696-1750), der in der Ihre-Dissertation nicht erwähnt wird. Vgl. etwa zu seinen etymologisch sehr gewagten Gleichsetzungen von Warägernamen in russischen und skandinavischen Quellen Scholz (2000. S. 286-299, insbesondere S. 292295). Die bei Peters (2003. S. 44 Anm. 210) angeführten Publikationen Björners sind hier bei Schlözer sicher weniger gemeint als die solche anstößige Gleichsetzungen enthaltende Schrift „Schediasma historico-geographicum de Varagis heroibus Scandianis et primis Russiae dynastis. Stockholmiae 1743“(vgl. Scholz 2000. S. 288).

47 Vgl. zu Ihre als Etymologen Holm/Jonsson 1990. S. 1936 zu Ihres „Glossarium Suiogothicum“ von 1769, ferner die Bemerkung bei Lindroth (1989. S. 608-609), daß Ihre den fabulösen Etymologien O. Rudbecks den Todesstoß versetzt habe, und davor die knappe Würdigung bei Moberg/Widmark/Andersson (1976. S. 72):

The person who laid the foundations of sound, scholarly etymological research was Johan Ihre (1707-1780), Sweden's greatest philologist during the eighteenth century. 
nicht gegen etymologische Beweisführungen überhaupt, sondern nur gegen Etymologie-Postulate, die in Ausdruck und Bedeutung der verglichenen Wörter die von ihm und seinen germanistischen Lehrern geforderte Regularität vermissen lassen und/oder historischen Tatsachen widersprechen ${ }^{49}$. Nicht zuletzt ist an dieser dem „Auszug" vorangestellten Notiz bemerkenswert, daß Schlözer eigens hervorgehoben hat, daß das mit der Dissertation bewiesene weitere geographische Verständnis von Girkia-Stellen in der Runenüberlieferung nicht nur für die schwedische Geschichte von Interesse ist, sondern auch Auswirkungen auf die Beschreibung der Geschichte der Alten Rus' haben kann, denn an eine solche Weiterung ist im Text der lateinischen Dissertation noch nicht gedacht. Da es sich hier vielleicht um den ersten selbständigen Gedanken handelt, den Schlözer zur mittelalterlichen Geschichte des ostslavischen Raums gefaßt hat, wäre sehr daran gelegen, wenn man noch erfahren könnte, wo, wann und für wen er seinen „Auszug" gefertigt hat. Unabhängig davon wissen wir durch dieses Dokument etwas genauer, worauf sich Schlözer hätte berufen können, als er sich im Frühjahr 1761 Müller mit der beiläufigen Bemerkung empfohlen hat, daß er während seines Aufenthalt in Schweden bei der Beschäftigung mit der Nordischen Geschichte „schon natürlicher Weise auch in die Russische Historie" geraten sei ${ }^{50}$.

Wegen ihres eher historischen Themas wird die Ihre-Dissertation 1763/ 64 in der „Rußischen Sprachlehre“ Schlözers verständlicherweise nicht eigens genannt, aber ihr Verfasser ist wie schon erwähnt nominell präsent, nicht zuletzt - noch immer fünf Jahre vor (!) der Veröffentlichung -

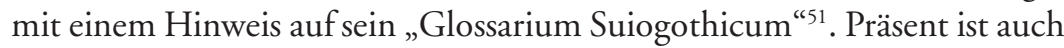
wieder Rudbeck als abschreckendes Beispiel allzu gewagten und deshalb verfehlt zu nennenden Etymologisierens, einerseits namentlich erwähnt:

Hier kommen sollen und debeo zusammen, zwei Wörter, deren Vergleichung selbst Rudbeck und Hermann von der Hardt nicht gewaget haben würden,

andererseits ohne Namensnennung bei der Zurückweisung der Versuche von Gelehrten des 17. Jh., die Ähnlichkeit zweier Sprachen allzu einfach zu erklären:

49 Vgl. aus seiner in der „Nordischen Geschichte“ publizierten knappen Methodenlehre für den Sprachvergleich den pointierten Satz: „Rudbeck erschaft Facta aus Etymologien: ich setze die Facta aus der Geschichte voraus, und bestärke oder erläutere sie aus der Etymologie“ (Schlözer 1771. S. 108, Hervorhebung im Original). Zu Schlözer als Etymologen vgl. Udolph 2000.

50 Vgl. Myl'nikov 1985. S. 647-648 und Schlözers zweifelsfrei noch vom Ende der fünfziger Jahre stammende Bemerkung über die skandinavische Herkunft der Waräger in der „Neuesten Geschichte der Gelehrsamkeit in Schweden“, auf die Peters 2003. S. 42 hinweist.

51 Bulič 1904. S. 29. 
Von zweien Sprachen, die einander ähnlich waren, mußte immer eine älter seyn als die andre, mußte immer eine die andre gezeugt haben. Und weil diese Etymologen zugleich Patrioten waren, so räumte jeder seiner Mutter-Sprache diese vermeintliche Vorzüge ein. Ein Holländer fand in seiner Sprache Worte, die zugleich verschiedene andre Sprachen hatten: sogleich schloß er, daß von seiner Mutter-Sprache alle andern in der Welt herkämen, und hörte in seiner Etymologischen Begeisterung schon im Paradiese Holländisch sprechen. Ein Schwede leitete aus gleicher Schwachheit alle andre Sprachen aus dem Schwedischen her, baute die Ehre seiner Nation auf das Altertum ihrer Sprache, und schalt mit allem Eifer eines Patrioten auf diejenige, so sich ihm zu widersprechen erdreisteten ${ }^{52}$.

Mit dem Holländer ist offensichtlich Johannes Goropius Becanus (15181572) gemeint ${ }^{53}$.

In der „Probe Rußischer Annalen“ von 1768 wird die Ihre/BeroniusDissertation mit genauer Seitenangabe („pag. 18. sq.“) an derjenigen Stelle herangezogen, wo es um die Herkunft der Waräger geht:

Wer sind die Waräger, aus denen sich die Nowgorodischen Slaven ihre Fürsten wählten? - Schweden waren es, sagt Dalin, und fast alle seine Landsleute: aber keiner beweiset es. So viel ist richtig, das Rußische Varâg, das Griechische Baraggoj, und das Schwedische Vering, ist ein und eben dasselbe Wort: doch mit einigem Unterscheide in der Bedeutung. Das Rußische ist der Name eines Volks, das Griechische und Schwedische aber der Name einer Bedienung. Die letztere Bedeutung scheint älter zu seyn, und die andre veranlaßt zu haben: denn nur bei jener hat die glückliche Herleitung des Hrn. von Ihre statt, der zu Folge es eine wörtliche Uebersetzung von Foederati ist ${ }^{54}$.

Auch in diesem Buch versäumt Schlözer es nicht, in der Nachfolge Ihres gegen Rudbeck zu Felde zu ziehen ${ }^{55}$.

Wie oben bereits angedeutet, wird der Text der lateinischen Dissertation von 1758 auf deutsch in der „Allgemeinen Nordischen Geschichte“ von

52 Bulič 1904. S. 47 bzw. 30. Zu Hermann von der Hardt (1660-1746) vgl. Borst 1961. S. 1473-1474 („der sprachenkundige, schrullige Helmstedter Orientalist“) und schon Jöcher 2.1750/1961. Sp. 1361-1364 („Die hebräische Sprache wollte er anfangs aus der arabischen, hernach aber beyde Sprachen nebst den übrigen morgenländischen Mundarten aus der griechischen Sprache herleiten.").

53 Vgl. Borst 1960. S. 1215-1218, ferner Vermeulen 2008. S. 52 und schon Jöcher 2.1750/1961. Sp. 1078-1079 („Er wollte die Leute bereden, daß die holländische Sprache die älteste und das Paradies in Holland gewest sey.").

54 Schlözer 1768. S. 79. Die Ableitung des Wortes von anord. vár „Treue, Bürgschaft, Gelübde“ gilt auch heute noch als die plausibelste Erklärung, vgl. Šanskij 1968. S. 21-22 nach Vasmer 1953. S. 171. Diese Etymologie Ihres gehört also zu den nicht wenigen richtigen, die Ihre, wie man geurteilt hat (Holm/Jansson 1990. S. 1936), erstaunlicherweise finden konnte, obwohl die Voraussetzungen dafür nicht sonderlich gut waren. Zu älteren Deutungen des Warägernamens vgl. Scholz 2000 passim, insbesondere zu den konkurrierenden skandinavischen Ansätzen Björners S. 291-292.

55 So sagt er 1768 nach der Behauptung, daß die Geschichte Rußlands mit der Staatsbildung durch Rurik anfange: 
1771 sehr ausführlich referiert, und zwar mit Angabe des Originals als erster Abschnitt des Kapitels VII unter der Überschrift „Von den Reisen der Skandinavier nach Constantinopel und in andre Länder, seit dem neunten Jahrhunderte " ${ }^{\text {56 }}$. Darüber hinaus erinnert an Schlözers oben zitierte prinzipielle Würdigung der Leistung Ihres, der die „Wortforschung [... ] mit der Geschichte wieder versöhnet u. ihre Ehre rettet“, an einer früheren Stelle die Charakterisierung der schwedischen Geschichtsschreibung:

In der ersten Hälfte des 18 ten Jahrhunderts räumten Wilde und Dalin in der mittlern Geschichte ihres Vaterlandes vortreflich auf, und erwarben sich grosse Verdienste: aber in der ältesten Periode vor dem Christenthum sind sie in der Hauptsache beyde noch ihrem fantasirenden Rudbeck getreu. Erst in unsern Tagen verändert die schwedische Geschichte ihre Gestalt: durch Vermittelung der Herrn Ihre und Celsius versöhnt sie sich allmählig mit der Kritik und dem guten Geschmack; und fängt an, um diesen Ausdruck einem berühmten Schriftsteller abzuborgen, aus einer See von Fabeln hervorzugehen, fast wie Dalin, noch kurz vor der jetzigen glücklichen Periode, Schweden selbst aus einem erdichteten Meer hervorsteigen ließ ${ }^{57}$.

Man beachte im übrigen, daß Ihre hier neben den Historiographen Magnus Celsius (von Celse; 1709-1784) und Olof von Dalin (1708-1763) nicht so sehr als Sprachwissenschaftler, sondern eher als Historiker vorgestellt wird. Auch sonst hat Ihre nicht wenig zur „Nordischen Geschichte“ Schlözers beigetragen $^{58}$, wie dieses Buch ja überhaupt ohne die in Schweden gesam-

Die Rußische Geschichte hat solchergestalt (welch ein Glück für den Geschichtforscher!) kein tempиs $\mu$ hüllten Anfang, in dem ein gelerter Wagehals auf Abenteur ausgehen und ein Rudbeck voll Witz, ein Wilde voll Belesenheit, Träume und Gesichter anbringen können (Schlözer 1768 S. 48-49),

und in der Qualifizierung eines Geschichtswerks als „mehr als Rudbeckisch“ ist der Name bereits zum pejorativen Adjektiv transformiert (S. 131). In der „Nordischen Geschichte“ spricht er von historisch absurdem Etymologisieren als „Rudbeckianismus“ („Vielleicht die Hälfte der Griechischen Mythologie hat diesem Rudbeckianismus ihr Daseyn zu danken.", 1771. S. 260), und in seinem "Chaldäer"-Aufsatz (1781. S. 171-172) hat er den Namen Rudbecks sogar metonymisch zur Bezeichnung schlechter Etymologen überhaupt („Ein Rudbeck der 1ste“ [= Cornelius Nepos], „Ein Rudbeck der 2te“) werden lassen.

56 Schlözer 1771. S. 541-556. Das oben in Anm. 40 bereits zitierte Fazit des letzten Satzes hat Schlözer hier mit den Worten angegeben:

Wann also Runsteine und Sagen jemanden in Griechenland oder Austr sterben lassen; so ist das Land dadurch nicht eigentlich bestimmt: es kann Estland und Rußland so gut wie Hellas und das Byzantinische Reich gemeinet seyn. (S. 556),

und dieses Ergebnis kann man hier auch schon früher lesen:

Rußland also muß sehr oft verstanden werden, wenn die alten Skandischen Nachrichten von Reisen der Skandinavier nach Griechenland reden (S. 504).

57 Schlözer 1771. S. 219.

58 So stammen von ihm z.B. auch die Abschnitte „Anhang von dem alten Quenland“ (S. 483490; = De Quenlandia antiqua [1767]), „Von der Schreibkunst in Skandinavien. Abschnitt 1 Vom Alter der Runen in Schweden“ (S. 527-593; = De runarum in Suecia antiquitate [1769]) und „Abschnitt 2. Vom Ursprunge der Runen überhaupt“ (S. 594-618; De runarum patria 
melten bzw. später von dort bezogenen Materialien die an ihm gerühmte Reichhaltigkeit der Informationen nicht hätte gewinnen können.

Schließlich wird der Dissertationsdruck von 1758 als eine der noch immer lesenswerten Untersuchungen zum Waräger-Problem sogar noch 1802 in der Kommentierung des "Nestor" empfohlen und dabei auch die von Ihre gefundene richtige Etymologie des Namens („,von dem Angelsächs. war, foedus") angeführt" .

Man kann also ohne Übertreibung sagen, daß die unter Ihres Ägide in Uppsala entstandene „Probschrift“ Schlözer mehr als vier Jahrzehnte begleitet und beschäftigt hat - von seinen ersten Schritten in die Sprachforschung und in die Geschichtsschreibung bis zu seinem historiographischen chef d'ouvre am Ende des Lebens. Daß Schlözer diesen Teil seines wissenschaftlichen Wegs so erfolgreich gehen konnte, verdankt er sicher neben seiner besonderen Begabung auch der gründlichen Ausbildung zunächst in Wittenberg und danach in Göttingen. Die überraschende Neuorientierung seiner wissenschaftlichen Interessen in den sechziger Jahren können wir aber nur dann richtig verstehen, wenn wir berücksichtigen, welche Anregungen er in der zweiten Hälfte der fünfziger Jahre bei seinem Studium in Uppsala und dort vor allem bei Johan Ihre erhalten hat, dem es offenbar gelungen ist, den verhinderten Orientreisenden für die Bearbeitung sprachhistorischer Probleme und für die Quellenkritik der mittelalterlichen Geschichte zu gewinnen. Auf der Schlözer-Tagung in Kirchberg Anfang September 2009 waren die Teilnehmer sich in der Schlußdiskussion einig, daß wir namentlich über Schlözers wissenschaftliche Entwicklung in Schweden bisher zu wenig informiert sind. Am Beispiel von Schlözer als Sprachforscher hat sich nun erwiesen, daß das in der Tat eine empfindliche Lücke in unserem Wissen ist, die nach Möglichkeit geschlossen werden sollte - dies um so mehr, als der deutsche Gast damals allem Anschein nach für seine späteren Arbeiten manche Anregung auch von der zeitgenössischen schwedischen Geschichtsschreibung erhalten hat.

et origine [1770]). Vgl. jetzt auch die Interpretation dieser beiden Runen-Dissertationen bei Östlund 2000. S. 83-293. Nur am Rande sei vermerkt, daß ein Ihre-Text auch hinter Schlözers Buch „Isländische Literatur und Geschichte“ aus dem Jahre 1773 steht, das jüngst noch einmal Aufmerksamkeit erregt hat, weil in ihm erstmals (und lange vor Goethe im Jahre 1827!) der Terminus Weltliteratur auftritt, vgl. Schamoni 2008 (für den Hinweis auf diesen Artikel bin ich meinem Bonner Kollegen Stefan Zimmer zu Dank verpflichtet). 


\section{Literatur}

Agrell 1955 - J. Agrell: Studier in den äldre språkjämförelsens allmänna och svenska historia fram till 1827. Uppsala/Wiesbaden 1955.

Borst 1960-1961 - A. Borst: Der Turmbau von Babel. Geschichte der Meinungen über Ursprung und Vielfalt der Sprachen und Völker. Bd. III. Umbau. Teil 1-2. Stuttgart 1960-1961.

Buhle 1794 - Literarischer Briefwechsel von Johann David Michaelis. Geordnet und herausgegeben von J. G. Buhle. Erster Theil. Leipzig 1794.

Bulič 1904 -Aug. Schlözer: Ruszische Sprachlehre. I.-II. / A. Šlecer: Russkaja grammatika. I.-II: S predisloviem S. K. Buliča. Sanktpeterburg 1904.

Dörfler/Weiß 2001 - A. Dörfler, H. Weiß: „Schlözer, August Ludwig“, Bio-bibliographisches Handbuch zur Sprachwissenschaft des 18. Jahrhunderts. Die Grammatiker, Lexikographen und Sprachtheoretiker des deutschsprachigen Raums mit Beschreibungen ihrer Werke. Bd. 7. Pe-Schr. Tübingen 2001. S. 344-349.

Grape 1949 - A. Grape: Ihreska handskrifts samlingen i Uppsala Universitets Bibliotek. Del I. Samlingen tillkomst och öden person- och lärdomshistoriska studier över dess innehåll; Del II. Kommenterande katalog. Uppsala 1949.

Haller 1760 - [Haller, A. von]: [Rezension zu Ihre 1758], Göttingische Anzeigen von Gelehrten Sachen 1760. S. 417-419.

Holm 1971-1973 - G. Holm: „Ihre, Johan“, Svenskt biografiski lexikon. 19. Stockholm 1971-1973. S. 763-770.

Holm 1996 - G. Holm: „Ihre, Johan“, Lexicon grammaticorum. Who's Who in the History of World Linguistics. Ed. by H. Stammerjohann. Tübingen 1996. S. 457458.

Holm/Jonsson 1990 - L. Holm, H. Jonsson: „Swedish Lexicography“, Wörterbücher. Dictionaries. Dictionnaires. Ein internationales Handbuch zur Lexikographie [...]. Bd. 2. Berlin, New York 1990. S. 1933-1943.

Ihre 1755 - J. Ihre (praes.) / C.G. Linroth (defen.): Vetustus catalogus regum Sviogothicorum, pars quinta. Upsaliae/Uppsala 1755 [vgl. Östlund 2000. S. 362].

Ihre 1758 - Disputatio academica, sistens peregrinationes gentium septentrionalium in Graeciam, cuius partem priorem [...] sub praesidio D[omini] Johannis Ihre, [...] pro gradu defendet Magnus Olavus Beronius, Uplandus. Upsaliae [1758].

Ihre 1769 - Glossarium Suiogothicum, in quo tam hodierno usu frequentata vocabula, quam in legum patriarum tabulis aliisque aevi medii scriptis obvia explicantur, et ex dialectis cognatis, Moesogothica, Anglosaxonica, Alemannica, Islandica ceterisque Gothicae et Celticae originis illustrantur. Auctore Johanne Ihre. Tomus prior. Tomus posterior. Upsaliae 1769.

Jöcher 1750/1961 - Chr. G. Jöcher: Allgemeines Gelehrten-Lexicon [... ]. Zweyter Theil. Leipzig 1750. Nachdruck Hildesheim 1961.

Keipert 2006 - H. Keipert: Das „Sprache“-Kapitel in August Ludwig Schlözers „Nestor " und die Grundlegung der historisch-vergleichenden Methode für die slavische Sprachwissenschaft. Göttingen 2006.

Keipert 2010 - H. Keipert: „August Ludwig Schlözer und die slavischen Sprachen“ [Beitrag zur Konferenz „Schlözer in Europa“, Kirchberg an der Jagst, 2.-5.9.2009 (im Druck)]. 
Lauch 1968 - A. Lauch: „August Ludwig von Schlözer - ein Wegbereiter der Slawistik vor Josef Dobrovský", Wissenschaftliche Zeitschrift der Humboldt-Universität zu Berlin, Ges.-Sprachw. R. 17,2. S. 275-282.

Lauer 1985 - R. Lauer: „Schlözer und die Grundlegung slavistischer Methodologie“, Zeitschrift für Slawistik 30,5.1985. S. 634-644.

Lindroth 1989 - S. Lindroth: Svensk lärdomshistoria I-IV. 2. Aufl. Stockholm 1989.

Moberg/Widmark/Andersson 1976 - L. Moberg, G. Widmark, T. Andersson: „Scandinavian languages“, Faculty of Arts at Uppsala University. Linguistics and Philology. Uppsala 1976. S. 71-87.

Mühlpfordt 1983 - G. Mühlpfordt: „August Ludwig Schlözer. 1735-1809“, Wegbereiter der deutsch-slawischen Wechselseitigkeit. Berlin 1983. S. 133-156.

Mühlpfordt/Zeil 1993 - G. Mühlpfordt, W. Zeil: „Schlözer, August Ludwig von“, Slawistik in Deutschland von den Anfängen bis 1945. Ein biographisches Lexikon. Bautzen 1993. S. 341-343.

Ohnheiser 1985 - I. Ohnheiser: „Schlözers Russische Sprachlehre“, Zeitschrift für Slawistik 30,4.1985. S. 544-554.

Östlund 2000 - Kr. Östlund: Johan Ihre on the Origins and History of the Runes. Three Latin Dissertations from the Mid $18^{\text {th }}$ Century Edited with Translation and Commentary. Uppsala 2000.

Peters 2003 - M. Peters: Altes Reich und Europa. Der Historiker, Statistiker und Publizist August Ludwig (v.) Schlözer (1735-1809). Münster, Hamburg, London 2003.

Raumer 1870 - R. von Raumer: Geschichte der Germanischen Philologie, vorzugsweise in Deutschland. München 1870.

Schamoni 2008 - W. Schamoni: „Weltliteratur - zuerst 1773 bei August Ludwig Schlözer", arcadia. Internationale Zeitschrift für Literaturwissenschaft 43,2.2008. S. 288298.

Schimpf 1982 - W. Schimpf: Die Rezensenten der Göttingischen Gelehrten Anzeigen. 1760-1768. Nach den handschriftlichen Eintragungen des Exemplars der Göttinger Akademie der Wissenschaften bearbeitet und herausgegeben. Göttingen 1982.

Schlözer 1756-1760 - Neueste Geschichte der Gelehrsameit in Schweden. 1.-5. Stück. Rostock/Wismar 1756-1760.

Schlözer 1763-1764 s. Bulič 1904.

Schlözer 1768 - A.L. Schlözer: Probe Rußischer Annalen. Bremen und Göttingen 1768.

Schlözer 1771 - A.L. Schlözer: Allgemeine Nordische Geschichte: Aus den neuesten und besten Nordischen Schriftstellern und nach eigenen Untersuchungen beschrieben und als eine geographische und historische Einleitung zur richtigen Kenntniß aller skandinavischen, finnischen, slavischen, lettischen und sibirischen Völker, besonders in alten und mittleren Zeiten, herausgegeben. Halle 1771.

Schlözer 1781 - A.L. Schlözer: „Von den Chaldäern“, Repertorium für Biblische und Morgenländische Litteratur. Achter Theil. Leipzig 1781. S. 113-176.

Schlözer 1802-1809 - A.L. Schlözer: Nestorь. Russische Annalen in ihrer Slavonischen GrundSprache verglichen, übersetzt und erklärt. Bd. 1-5. Göttingen 1802-1809.

Schlözer 1802a - August Ludwig Schlözer's öffentliches und Privat-Leben, von ihm selbst beschrieben. Erstes Fragment. Aufenthalt und Dienste in Rußland vom J. 1761 bis 1765. Litterar-Nachrichten von Rußland in jenen Jaren. Göttingen 1802. 
Scholz 2000 - B. Scholz: Von der Chronistik zur modernen Geschichtswissenschaft. Die Warägerfrage in der russischen, deutschen und schwedischen Historiographie. Wiesbaden 2000.

Šanskij 1968 - Ėtimologičeskij slovar’ russkogo jazyka. Pod rukovodstvom i redakciej N. M. Šanskogo. I,3. Moskva 1968.

Udolph 2000 - J. Udolph: „A.L. Schlözer und die slavische Namenforschung“, Onomastické práce IV. Sborník rozprav k sedmdesátým narozeninám I. Lutterera. Praha 2000. S. 459-481.

Vasmer 1953 - M. Vasmer: Russisches etymologisches Wörterbuch. Erster Band. Heidelberg 1953.

Vermeulen 2008 - H.F. Vermeulen: Early History of Ethnography and Ethnology in the German Enlightenment: Anthropological Discourse in Europe and Asia, 1710-1808. Leiden 2008.

Winter 1961 - August Ludwig von Schlözer und Rußland. Eingeleitet und unter Mitarbeit von I. Richter und L. Zeil hrsg. v. E. Winter. Berlin 1961.

Wachter 1737 - J.G. Wachter: Glossarium Germanicum continens origines et antiquitates totius linguae Germanicae, et omnium paene vocabulorum vigentium et desitorum. Opus bipartitum et quinque indicibus instructum. Lipsiae 1737.

Zeil 1994 - W. Zeil: Slawistik in Deutschland. Forschungen und Informationen über die Sprachen, Literaturen und Volkskulturen slawischer Völker bis 1945. Köln, Weimar, Wien 1994. 